\title{
PERFIL DE MULHERES EM IGREJAS ORGÂNICAS NO BRASIL
}

\author{
Rebecca Ferreira Lobo Andrade Maciel*
}

\section{RESUMO}

Na década de 1980, publicações emergiram de uma necessidade social de entender o que estava ocorrendo no campo religioso, onde o catolicismo perdia sua hegemonia e novas experiências religiosas ganhavam força. Um dos grupos que ganhou força nesse período é do de Igrejas Orgânicas. Sendo igrejas em espaços domésticos e públicos, sem vínculo com denominações evangélicas, acabam se tornando um refúgio para mulheres que desejam sair de seu meio institucional. Nosso objetivo, então, é analisar a relação entre demandas de gênero e adesão de mulheres a igrejas orgânicas. Para isso, analisamos um vasto material bibliográfico e foram aplicados 392 questionários on-line, com o total de 17 perguntas quantitativas e qualitativas, por todo o Brasil, a fim de obter novos dados estatísticos acerca deste campo. O atual artigo traz a primeira análise do perfil religioso e social destas mulheres.

Palavras-chave: Gênero. Religião. Igrejas Orgânicas. Evangélicos.

\section{PROFILE OF WOMEN IN ORGANIC CHURCHES IN BRAZIL}

\section{ABSTRACT}

In the 1980s, publications emerged from a social need to understand what was going on in the religious field, where Catholicism was losing its hegemony and new religious experiences gained momentum. One of the groups that gained strength during this period is that of Organic Churches. Being churches in domestic and public spaces, unconnected with evangelical denominations, they end up becoming a refuge for women who want to leave their institutional milieu. Our goal, then, is to analyze the relationship between gender demands and women's adherence to organic churches. For this, we analyzed

* Mestra em Ciências da Religião pela UMESP. Especialista em Ciência da Religião pela FSBRJ. Psicóloga pela UFRJ. Teóloga pela Unibennett. 
a vast bibliographic material and 392 online questionnaires were applied, with a total of 17 quantitative and qualitative questions, all over Brazil, in order to obtain new statistical data about this field. The current article brings the first analysis of the religious and social profile of these women.

Keywords: Gender. Religion. Organic Churches. Evangelicals.

\section{PERFIL DE MUJERES EN IGLESIAS ORGÁNICAS EN BRASIL}

\section{RESUMEN}

En la década de 1980, las publicaciones surgieron de una necesidad social de comprender lo que estaba sucediendo en el campo religioso, donde el catolicismo estaba perdiendo su hegemonía y las nuevas experiencias religiosas cobraron impulso. Uno de los grupos que ganó fuerza durante este período es el de las Iglesias Orgánicas. Al ser iglesias en espacios domésticos y públicos, sin conexión con denominaciones evangélicas, terminan convirtiéndose en un refugio para las mujeres que desean abandonar su entorno institucional. Nuestro objetivo, entonces, es analizar la relación entre las demandas de género y la adhesión de las mujeres a las iglesias orgánicas. Para esto, analizamos un vasto material bibliográfico y se aplicaron 392 cuestionarios en línea, con un total de 17 preguntas cuantitativas y cualitativas, en todo Brasil, para obtener nuevos datos estadísticos sobre este campo. El presente artículo trae el primer análisis del perfil religioso y social de estas mujeres.

Palabras clave: Género. Religión. Iglesias orgânicas. Evangélicos.

\section{INTRODUÇÃO}

Essa pesquisa, realizada em meu mestrado, condensa tudo isso que me transpassa no âmbito de fé, igreja, gênero e de mobilidade religiosa. O objetivo desta pesquisa era analisar as relações que existem entre as demandas de gênero para o trânsito religioso de mulheres e a sua adesão às igrejas orgânicas. Contudo, nesse processo, eu precisei analisar quais mulheres eram estas, de onde vieram e quais suas demandas, já que não havia nenhum dado acerca disso.

Sandra Duarte de Souza (2001) enfatiza a dupla marginalidade de uma pesquisa como esta: primeiro, por ser sobre religião, um tema pouco trabalhado nas Ciências Sociais; e segundo, por ser sobre gênero. Recentemente, os estudos de gênero estão se expandindo a fim de suprir as 
lacunas ainda existem - principalmente quanto às mulheres evangélicas (Márcia Thereza COUTO, 2002; Rubem César FERNANDES, 1998; Maria das Dores Campos MACHADO; Fabiana Melo de FIGUEIREDO 2000; Sandra Duarte de SOUZA, 2015; Valéria Cristina VILHENA, 2009). Estas mulheres, que sempre foram atuantes em suas comunidades e são peças fundamentais para se entender o protestantismo brasileiro, são colocadas ainda como um subgrupo de menor importância para a análise.

Assim, foi feita uma pesquisa bibliográfica a partir de livros e artigos e a segunda parte foi a coleta de dados a partir de um survey online, um questionário virtual enviado para as mulheres dessa igreja. Foi solicitado às entrevistadas a assinatura do termo de autorização, tornando-as aptas para responder às perguntas. As mulheres forneceram seus dados socioeconômicos para mapeamento de classe e raça/etnia. Assim, as perguntas se dividiram sobre o que elas creem e sua relação com a comunidade orgânica. Perguntou-se, ainda, o nome da comunidade, as características, o tempo que participa, a experiência de pertencimento, o grau de envolvimento, se tem função na comunidade e a frequência da participação. Foram perguntados, também, os motivos da adesão e se participavam de outros grupos religiosos. Ao perguntarmos sobre as crenças, buscamos também saber a influência de meios de informação e quais são as necessidades para manter a fé. Com isso, formamos um questionário de dezessete perguntas quantitativas e duas qualitativas. Assim, a pesquisa conduz a um caminho de descoberta a respeito de quem são essas mulheres e suas motivações, quais são seus trajetos de rupturas e continuidades frente às denominações evangélicas e seus desejos para a vivência religiosa.

Nossa pesquisa foi realizada via internet, a partir do modelo de survey recomendado pelo Google. Assim, todo acesso à pesquisa foi virtual e não houve entrega presencial de questionários. Não sabemos precisamente, então, como foi a acolhida das pessoas frente à pesquisa. Porém, houve algumas pessoas que fizeram questão de opinar sobre a pesquisa, e tivemos silêncios que cabem na análise.

Foram 10 mensagens enviadas para mais de 50 endereços eletrônicos, 53 mensagens de WhatsApp para líderes do Caminho da Graça, 23 para os da EQUI Orgânica, postagens no grupo Igreja Orgânica/Organic 
Church e postagem patrocinada, ou seja, paga, na página Religar-se. A grande maioria foi respondida com silêncio, sem resposta positiva ou negativa a respeito. Isso aponta para algumas hipóteses: mesmo sendo uma pesquisa gratuita, anônima e pouco demorada, não há uma cultura de resposta a questionários acadêmicos. Além disso, posso suspeitar que, pela controvérsia do tema, haveria resistência quanto às respostas.

\section{PERFIL SOCIAL}

O perfil social destas mulheres era um dos maiores enigmas por trás desta pesquisa. Afinal, nós tínhamos parâmetro de quais seriam seus interesses religiosos, onde estas mulheres poderiam morar e até mesmo qual poderia ser o perfil etário a partir da participação delas nas redes sociais. Porém, nada disso era consistente e suficiente para considerar quais mulheres eram estas que diziam participar de igrejas orgânicas. Por isso, na pesquisa, era primordial descobrir que mulheres eram estas. O primeiro fato interessante é observado na sua faixa etária.

A preponderância é entre jovens e jovens adultas (79,3\%). Se somarmos as jovens de 15 a 20 anos e mulheres com mais de 45 anos, temos aproximadamente $20 \%$. Assim, podemos perceber que as mulheres de igrejas orgânicas são jovens ou jovens adultas de alto nível intelectual, porém nem sempre isso se reflete na sua condição financeira. Comparando com os/as evangélicos/as indicados pelo IBGE (2010), estas estão acima da média financeira e de escolaridade com relação aos/às adeptos/ as desta religião. Contudo, elas se encontram, majoritariamente, em estados onde os/as evangélicos/as são mais representativos/as.

Usando o parâmetro de outras fontes sobre igrejas orgânicas, como o grupo oficial do Facebook, as páginas da EQUI orgânica, Caminho da Graça e Missão 20:20, tivemos uma proporção muito parecida com a que conseguimos de mulheres pelo survey. São 35 mulheres no Sudeste que só vão a igrejas orgânicas, sendo 94 brancas, 27 negras e 48 pardas. Assim, observando tais dados desta região, uma minoria apenas frequenta igrejas orgânicas e é este grupo que possui a maior escolarização no meio. São mulheres que, majoritariamente, vieram de igrejas evangélicas e são brancas, o que se diferencia também da realidade geral do povo evangélico pelo IBGE (2010). A presença no Sudeste é evidente em 
grupos como o Caminho da Graça e EQUI orgânica. Além disso, vemos um número extremamente alto de mulheres com passagem em diversas igrejas evangélicas e de outras religiões. Devido à pluralidade religiosa em cidades como Rio de Janeiro e São Paulo, é provável que isso facilite o acesso a diferentes espiritualidades. É também curioso porque o polo da EQUI orgânica é em Gramado, na região Sul, sendo que Caio Fábio mora em Brasília, na região Centro-Oeste. Todavia, a presença rigorosa se encontra no Sudeste. Nesse território, temos, também, grande presença de mulheres que responderam ao questionário e se diziam de igrejas denominacionais. Estas, além daquelas que vão prioritariamente a igrejas orgânicas, compõem as mulheres da região Sudeste.

A presença no Sul e no Nordeste também é importante. Unindo essas duas regiões, temos $28 \%$ das mulheres que dizem fazer parte de igrejas orgânicas. No Nordeste são 32 mulheres. Quando observamos o campo das igrejas orgânicas, o Sul e o Sudeste sempre estavam disputando o segundo lugar de sua maior presença. O nível social é similar ao do Sudeste e muitas destas mulheres advêm de igrejas pentecostais, mesmo no caso das mulheres do Sul. É interessante de se observar, pois essa pertença anterior influencia suas crenças. O fato da presença do Espírito Santo ser tão importante para mulheres de igrejas orgânicas provavelmente está relacionado a esse histórico. Uma minoria está no Norte e no Centro-Oeste, mesmo tendo um dos grandes líderes - Caio Fábio - morando em Brasília. Isso pode indicar que não é somente a figura de Caio Fábio que atrai mulheres ao Caminho da Graça ou a outras igrejas orgânicas.

O estado civil dessas mulheres também é interessante observar, afinal, quase metade das mulheres da pesquisa é casada. Solteiras chegam a $38,1 \%$. Viúvas, divorciadas e mulheres em união estável - que sofreriam mais preconceito social - são 10\%. Essa porcentagem pode indicar que há uma aproximação destas mulheres às igrejas orgânicas, mas não chega a ser o público principal. São 142 mulheres casadas ou em união estável que têm filhos/as, sendo 98 sem filhos/as. Estas são mulheres normalmente de 30 a 45 anos. Dentre os motivos que levam as mulheres a fazerem parte de igrejas orgânicas, vemos de modo bastante presente a importância da família participar dessa comunidade. Isso faz bastante sentido para mulheres casadas. 
Ainda dentro do tema da família, entre as mulheres que responderam ao survey, 53,6\% não têm filhos e 46,4\% têm. Quanto à profissão, há um número grande de professoras e estudantes, além de profissionais liberais. 46 são estudantes, 13 do lar e todas as outras trabalham de algum modo. Observando mais detalhadamente os dados, é uma minoria que possui filhos/as e não está casada. Isso demonstra que a maioria das famílias que aparecem nas igrejas orgânicas são de casais jovens com filhos/as enquanto figuras menos aceitas socialmente - como mães solo, etc. - não aparecem tanto nessas comunidades. O fato de ser grande o número de mulheres sem filhos/as nessa comunidade também está vinculado à faixa etária destas, que são jovens, estudantes universitárias e estão desempregadas.

Um pouco mais da metade está empregada e 41,5\% estão desempregadas, 110 mulheres e 85 destas recebe de 1 a 3 salários mínimos. São pessoas que têm formação e, mesmo assim, estão desempregadas. Doze das mulheres desempregadas são negras, 24 são pardas e 49 são brancas. Esses números estão muito acima da média nacional. Em 2017, tivemos $12,7 \%$ de desempregados/as, isso é uma fração que não chega a metade das que se dizem de igrejas orgânicas. O recorde brasileiro foi de $13,7 \%$, ainda distante da realidade do survey, e, no caso de mulheres evangélicas, no ano de 2010, eram 9\%.

Nos dados do survey, também podemos perceber outras minúcias quanto ao desemprego. São $70 \%$ das mulheres de 20 a 30 anos que estão desempregadas, e esta é uma faixa etária muito importante para o público de igrejas orgânicas. Olhando para a média evangélica do país, temos cerca de $43 \%$ de pessoas desempregadas no meio evangélico, o que está acima da média nacional, porém ainda abaixo no caso das mulheres de igrejas orgânicas. Contudo, o tema do desemprego não surge nas motivações.

Como muitas delas são solteiras, podemos imaginar que vivem na casa de seus pais e não sentem a necessidade imediata do emprego. No caso das mulheres casadas, esse tema se complexifica pela necessidade de manter uma casa. Entretanto, é curioso observar que dentro das motivações o tema do desemprego não foi levantado como muito importante, o que nos faz considerar a relação destas mulheres com a 
necessidade de estarem empregadas. Podemos considerar que, como muitas delas são casadas, pode ser que sejam dependentes financeiramente pelo emprego do marido.

Dentre as mulheres que responderam o survey, 63,4\% afirmaram que recebem de 1 a 3 salários mínimos, porém como esta era uma pergunta obrigatória, pode ser que uma porcentagem, na verdade, estivesse desempregada e não tinha como indicar que não possuía salário. Essa porcentagem é bem menor do que a de mulheres evangélicas com 1 a 3 salários mínimos indicadas pelo IBGE (2010), que é de $83 \%$.

Quase 30\% ganham de 4 a 10 salários mínimos e 7\% têm mais de dez salários mínimos, demonstrando que $37 \%$ são de classes mais favorecidas. Observando outros dados brasileiros, apenas $9 \%$ das mulheres evangélicas têm entre 4 e 10 salários mínimos e só $2 \%$ têm mais de 10 salários mínimos. Isso demonstra que as mulheres evangélicas que estão em igrejas orgânicas diferem muito das outras no sentido financeiro, mesmo estando acima da média em desemprego. Por isso, é muito provável que esta fonte de renda venha de outros, como pais e maridos, pois estas representam uma classe pobre. Podemos indicar, pela quantidade de mulheres que recebem entre 1 e 3 salários mínimos, que há sim uma classe média-baixa, porém ainda assim tem o nível econômico muito maior do que a média evangélica.

O mesmo ocorre com a escolaridade. Mais da metade das muIheres têm acesso ao ensino superior, $61,1 \%$ delas têm ensino superior completo e $23,8 \%$ incompleto, demonstrando que é uma classe média intelectualizada. Apenas 10\% têm ensino médio ou menos. Considerando que a pesquisa identificou 79 mulheres que se dizem unicamente de igrejas orgânicas, o fato de 57 delas terem ensino superior completo ou incompleto demonstra um alto índice de escolaridade nesse nicho. Isso tem relação com o fato das mulheres serem exigentes com o ensino bíblico nas igrejas e, como demonstram suas motivações, como o fato de uma "teologia mais bíblica" ser fator importante para a adesão. São mulheres que também têm formação, mas que não estão exercendo, pelo alto índice de desempregadas. Percebemos que elas valorizam mais o estudo do que o emprego imediato, o que é um fator comum na classe média. 
Além disso, é impossível falar de classe sem falar de raça/etnia também. A maioria das mulheres que responderam o survey são brancas. Mais especificamente: $55,5 \%$ brancas, $14,7 \%$ negras e $28,7 \%$ pardas, o que daria $43,4 \%$ do grupo como não-brancas. Outras respostas foram contabilizadas como pardas. Importante lembrar que, no Brasil, $53,6 \%$ das pessoas são negras e pardas, entendendo como pardas, principalmente, mulheres negras de pele clara. No caso das igrejas orgânicas, apesar da população negra e parda ser maioria no meio evangélico, isso não se repete nestes dados. Possuímos cerca de $10 \%$ a menos de negros em igrejas orgânicas do que no Brasil em geral e, no caso das mulheres evangélicas, $9 \%$ a menos. Dentro da categoria "outros", não recebemos relatos de mulheres asiáticas e indígenas, apesar destas estarem presentes no meio evangélico. Além disso, se formos dividir entre as mulheres que só vão a igrejas orgânicas, 30 das 79 são negras e pardas, o que dá $37 \%$ - porcentagem ainda menor do que o dado geral do nosso survey.

As mulheres brancas compõem $44 \%$ das mulheres evangélicas no Brasil (IBGE, 2010), enquanto, no caso de igrejas orgânicas, são 11,5\% a mais do que isso. No caso de mulheres que dizem só ir a igrejas orgânicas, o número aumenta: $63 \%$, ainda mais distante da média nacional de mulheres evangélicas. Esse é um dado evidente que aponta que quanto mais ricas e mais acesso ao ensino superior, mais provável que menos negras apareçam, devido ao racismo estrutural de nossa sociedade.

Desse modo, é possível perceber uma pluralidade dentro das mulheres de igrejas orgânicas quanto às características sociais, porém ainda há um padrão muito evidente. São mulheres majoritariamente brancas, com alto nível de instrução, jovens - e que quanto mais jovem, mais solteiras, e quanto mais adultas, mais casadas. $O$ índice de desemprego é bastante alto e, observando as mulheres que somente vão a igrejas orgânicas, o nível social fica ainda mais elevado. O ponto de menor convergência, apesar da maioria advir de igrejas evangélicas, é sua trajetória religiosa, assunto essencial para entender as motivações. 


\section{PERFIL RELIGIOSO}

O perfil religioso das mulheres que responderam foi bastante plural e, para isso devemos entender as principais questões que levantamos para perceber essa identidade religiosa. Primeiramente, tivemos aquelas que disseram ser somente de igrejas orgânicas e aquelas que se dizem de igrejas orgânicas, mas também relatam sua pertença a uma igreja institucional. Foram 265 mulheres que responderam, sendo 79 de comunidades orgânicas ou que não fazem parte de um grupo que deseja dizer o nome. As outras 186 são mulheres vinculadas a instituições que, por diferentes razões, dizem fazer parte de igrejas orgânicas. Contudo, é interessante para a análise separar esses dois grupos a fim de entender que estes possuem características que às vezes diferem, mas que se encontram. Os perfis das mulheres que vão somente a igrejas orgânicas e das que dizem ir em igrejas orgânicas, mas fazem parte também de alguma denominação evangélica, são bem parecidos socialmente, diferenciando nos casos somente de igrejas orgânicas, nos quais elas são mulheres com maior índice de escolaridade, brancas e de classe média mais alta. O mesmo ocorre com o perfil religioso. Elas, no geral, têm perfis similares de crenças, com pequenas diferenças, como acontece com a crença em Deus. Somente uma mulher respondeu que não cria em Deus e fazia parte de uma igreja orgânica. Podemos falar que o problema foi do termo e que, na verdade, seria crença total das mulheres, pois ela falou que a única crença dela é em Jesus. Contudo, a escolha pela pessoa de Jesus é interessante, pois ele está em $4^{\circ}$ lugar dentro das crenças mais comuns, mesmo todas se considerando evangélicas.

Quanto às suas crenças, 264 mulheres dizem crer em Deus; 236, no Espírito Santo; 232, na Bíblia. A crença em Jesus foi relatada por 202 entrevistadas. $O$ padrão se repete nas crenças principais destas mulheres: 203 dizem crer no céu; 184, no inferno; 177, no batismo no Espírito Santo; 168, na ressurreição; 152, em anjos; 141, em demônio; e 138, em línguas estranhas. Estas são as crenças principais das entrevistadas, acreditadas por mais de 50\% delas. Além destas, 116 mulheres dizem crer em revelações; 62, em espíritos; 46, em energia; e 41, em batismo infantil.

A média do survey todo é de mulheres brancas; majoritariamente de igrejas denominacionais, onde são membros; buscam uma "teologia 
mais bíblica" e "menos hierarquia"; vieram de outros grupos religiosos; não vão a outras igrejas e não consomem mídia religiosa. Separando deste grupo somente mulheres de igrejas orgânicas, encontramos um padrão levemente diferente.

Percebemos que, no que diz respeito às mulheres que vão somente a igrejas orgânicas, temos uma ênfase maior na questão da menor hierarquia e quase todos os casos são de mulheres que vieram de outros grupos religiosos. Dentre as 79 mulheres desse nicho, 78 vieram de outras comunidades. O fator da "teologia mais bíblica" fica em terceiro lugar, enquanto no caso das mulheres de igrejas denominacionais essa prioridade muda.

Entre as mulheres que vieram de igrejas denominacionais, temos um número bem menor que veio de outros grupos religiosos, de membros em suas comunidades, e priorizam uma "teologia mais bíblica" a uma igreja menos hierárquica - que fica em terceiro lugar dentre as opções assinaladas. Nos dois casos, em segundo lugar fica a busca por uma igreja onde estava a família.

Dentre as necessidades que estas mulheres possuem de viver sua fé, utilizamos os mesmos tipos de parâmetros para crenças: acima de $50 \%$, entre $49 \%$ e $10 \%$ e abaixo de $10 \%$. Acima de 50\% estão "oração" e "Bíblia"; entre 49\% e 10\%, "culto", "pertencer", "batismo" e "pastor(a)"; de 9\% a 1\% tivemos "templo", "missa", "santos", "objetos místicos", "novena”, "padre”, "benção religiosa”, "fé”, "Jesus" e "coerência”; menos de 1\%, "música" e "natureza"; nenhuma resposta para "Espírito Santo", "transformação da sociedade", "Deus", "livros dos mórmons" e "renovação carismática".

O perfil das mulheres que precisam da Bíblia e de oração são muito similares ao das mulheres identificadas com as crenças principais citadas. Encontramos uma maioria branca, que se diz de igrejas denominacionais. Estas mulheres são membros de suas comunidades, tendem a buscar a igreja pela questão da "teologia mais bíblica", de uma menor hierarquia e pela família. Além disso, a maioria veio de comunidades anteriores, não tem grande costume de visitar outras e não é muito achegada à mídia religiosa.

Contudo, encontramos mulheres que relatam precisar de fatores que são bastante improváveis a mulheres de igrejas orgânicas: 72 mu- 
Iheres (27\%) ressaltam o "culto"; 47 (17,7\%), o "pertencimento a um grupo religioso"; 39 (14,7\%), "batismo"; 39 (14,7\%), "pastor(a)" e 24 (9\%), "templo". É interessante observar que a porcentagem de mulheres que precisam destes elementos tão comuns nas igrejas é minoria, porém, não tão pouca assim, o que pode nos indicar uma diferença entre mulheres que vão a igrejas institucionais e as que vão somente a igrejas orgânicas.

A necessidade de culto, de pertença, de pastor, de batismo e de templo aparece na resposta de 72 das 184 mulheres que vão a igrejas institucionais, isto é, $38 \%$. No caso das mulheres em igrejas orgânicas, o número chega a $34 \%$ e, se retirar o pertencer, cai para 13. Ainda assim, é interessante observar essa porcentagem em mulheres que só vão a este tipo de igreja.

Estas também foram perguntadas se já haviam participado de outros grupos religiosos: $74,3 \%$ disseram que sim e $25,7 \%$, não. A maior parte das mulheres que responderam disse que havia passado por pelo menos duas igrejas evangélicas - históricas, pentecostais ou variando entre estas. Uma minoria, porém, passou por outras religiões, citando em sua maioria o candomblé e o espiritismo antes de conhecerem as igrejas orgânicas. Como observamos no trânsito religioso brasileiro, Sílvia Fernandes (2008) comenta que os/as evangélicos/as de igrejas históricas tendem a migrar para o pentecostalismo, catolicismo e/ou internamente. Pentecostais também costumam migrar para o mesmo segmento ou para igrejas históricas. Além dos dados específicos do meio evangélico, Sílvia Fernandes (2008) chama a atenção para o grande número de pessoas sem religião que vieram do meio evangélico (29\%), como podemos ver também nos dados de nosso survey. Metade das mulheres se consideram não religiosas e vieram de igrejas evangélicas. Então pode ser que, nessa pesquisa, nós estejamos não só observando os dados de trânsito intraevangélico, mas também dos/as "sem religião".

Entendendo que PIB é uma sigla para Primeira Igreja Batista, temos um total de 71 mulheres que vieram da Igreja Batista. Assim sendo, a referência principal das mulheres quanto à experiência de igrejas é advinda do meio batista e sua organização. Unindo também os termos que identificam os/as católicos/as, temos 37 pessoas; juntando as presbiterianas, 15 mulheres. Percebemos algumas características 
interessantes. A maior religião do Brasil ainda hoje é a católica, porém, em nossa pesquisa, ela aparece em $3^{\circ}$ lugar. Isso significa que, sim, o trânsito católico para as igrejas orgânicas existe, contudo, não é o mais comum. Além disso, vemos que a Assembleia de Deus, a maior igreja evangélica do Brasil, aparece em segundo lugar, o que demonstra um forte trânsito entre pentecostalismo e as igrejas orgânicas. Contudo, mesmo com a grande presença da Assembleia de Deus e de outras igrejas pentecostais, é interessante observar a presença da Igreja Batista, em primeiro lugar, como sendo a "doadora" maior de seus membros para as comunidades orgânicas.

O parâmetro de igrejas para aquelas que vão para as comunidades orgânicas é de igrejas históricas ou pentecostais de $1^{\mathrm{a}}$ onda (Ricardo MARIANO, 2008) e não tanto de igrejas neopentecostais. A partir destes dados, podemos perceber que não há somente um fluxo dentro do meio evangélico.

Questionamos também se elas consomem algum programa religioso: $61,9 \%$ não e $38,1 \%$ sim. Em primeiro lugar, vídeos de pregação no YouTube (55), televisão (16), rádio (6) e por último podcast (2), música (2) e outros (3). Todos estes são de instituições religiosas e possuem tendências teológicas muito diferentes - como a missão integral e o fundamentalismo. Encontramos também nomes de igrejas institucionais, como Universal, IBAB e Presbiteriana, no quesito pregações consumidas por essas mulheres.

Por fim, temos outras temáticas, como a "música", o "reformado", "Deus", "culto" e outras palavras. Assim, estas mulheres apresentam uma maior tendência a procurar pregações de diferentes fontes por interesse em pastores/as ou temas específicos. Interessante também perceber que não há relato de nenhum programa sobre mulheres ou nomes femininos. As 101 mulheres que consomem mídia religiosa ficam bem divididas no que diz respeito à questão racial, sendo 56 brancas e 45 pardas/negras. A maioria é de igreja denominacional (74), membros de suas igrejas (83), já frequentaram outros grupos (83), não costumam frequentar outras religiões (79) e se dividem bem entre as que se consideram religiosas (52) e as que não se consideram (50). Desse modo, aquilo que estas mulheres conhecem a partir da mídia, de sua 
família, de visitas e de crenças as compõem na hora de escolherem as comunidades de fé e suas motivações. Sua frequência, seus trânsitos, seus consumos de mídia religiosa são desenvolvidos a partir de seus motivos religiosos e, por isso, esta é a pergunta central deste trabalho.

\section{CONCLUSÃO}

A partir das análises de Sandra Duarte de Souza (2001), Maria das Dores Campos Machado e Cecília Loreto Mariz (2005), e outros/as autores/as, percebemos que a ideia de uma religião sem trocas contextuais não aparece na vida destas mulheres, mas sim fluida devido à troca de pessoas e de crenças. Por exemplo, um grupo grande de mulheres não se consideram religiosas e, por isso, podem se apresentar sem religião antes de se indicarem evangélicas, mesmo dizendo pertencer a igrejas orgânicas e tendo crenças comuns a esse grupo religioso - Deus, Bíblia, Espírito Santo e Jesus. As mesmas autoras apontariam que os/as "sem religião" são receptores/as, principalmente, de pentecostais e de católicos/as, além de alguns de igrejas históricas. Isso demonstra que o tipo de trânsito que estas mulheres constroem não entra dentro de um modelo, mas pode ser entendido por pesquisas que possuem tipologias para tal, como a que Sandra Duarte de Souza (2007) realizou.

Comentamos, durante a nossa pesquisa sobre definições que chegam mais perto do IBGE (2010), e apontam também para igrejas orgânicas, existências evangélicas que foram teorizados por diversos/ as autores/as no mundo, como Neil Cole (2007). Elas podem ser vistas como mulheres "sem religião", pois se afastam da igreja institucional, e, concomitantemente, da ideia de religião. Elas podem ser vistas também como mulheres de igrejas históricas ou pentecostais, pois muitas delas advém da igreja batista ou da igreja Assembleia de Deus e não fizeram um rompimento claro. E, por fim, essas mulheres podem ser chamadas de "evangélicas não determinadas" (IBGE, 2010), "evangélicos sem vínculo institucional” (IBGE, 2000), pois estas não se encaixam em uma denominação evangélica. Percebemos, então, rotas improváveis, paralelas os estudos de trânsito religioso e que até mesmo os estudos de gênero deixam de observar. Esse talvez seja um dos desafios futuros para as pesquisas de motivações de gênero para o trânsito religioso: 
perceber que a figura da mulher não entra em um tipo de trânsito específico e, particularmente, temos muito a conhecer acerca do trânsito para igrejas orgânicas. Na nossa pesquisa constatamos que as mulheres demonstram variações, não seguindo à risca o que a teoria diz sobre igrejas orgânicas.

Temos o discurso solidificado sobre o que seriam estas igrejas orgânicas. Percebendo pontes entre o "biblicismo" de Frank Viola (2010), a organicidade de Neil Cole (2007), as estruturas de Wolfgang Simson (2014) e as questões sociais de Felicity Dale (2014). A partir das características levantadas no survey, percebemos que para as mulheres, o principal aspecto é a "fé como um estilo de vida" - no patamar de $81,3 \%$, é a única que mais da metade das mulheres citou. Nesse momento, já surgiam em nossa pesquisa indícios de que as mulheres construíam a sua noção de igrejas orgânicas de modo muito próprio, sem realmente valorizar características fechadas de um/a autor/a ou outro/a. As estruturas não são a característica mais importante, mas a forma em que vive, demonstrando assim o desejo por coerência dentro das igrejas orgânicas.

Assim, adentrando esse mundo de crenças e de espiritualidade construído por essas mulheres, descobrimos um pouco mais de quem elas são: geralmente, mulheres brancas, de classe média, com ensino superior completo, casadas, engajadas em suas igrejas e sem muito interesse por frequentar outras comunidades. Quanto mais afinávamos o recorte para mulheres que assumiam ir prioritariamente à igrejas orgânicas, mais percebíamos a elitização dessa população: um número mais elevado de brancas com ensino superior completo e do sudeste brasileiro.

Apesar de disperso em diferentes estados do Brasil e com diferentes igrejas originárias, encontramos tal perfil através do survey com respostas de 265 mulheres. Um perfil de mulher evangélica distante do apresentado pelo IBGE (2010): negra, pobre e com baixo nível de escolaridade. Essa é uma das questões que pode ser levantada dentro da pesquisa: o quanto o trânsito destas mulheres representa as outras evangélicas e onde elas se encaixam dentro desse meio religioso tão plural? Em um país racista, altamente desigual e com alto nível de analfabetismo, os dados raciais e culturais precisam de uma pesquisa 
mais qualitativa.

Em nosso survey, questionamos quais eram as crenças destas muIheres, apresentando várias opções comuns no linguajar religioso, e deixamos estas dizerem em suas palavras também se tinham alguma crença particular. Estas mulheres intelectuais têm crenças muito comuns para o meio evangélico - Deus, Bíblia, Jesus e Espírito Santo - e precisam de costumes corriqueiros da fé cristã como o estudo da Bíblia e a prática da oração.

A presença de crenças, como em "energia", e de necessidades, como de "culto", nos mostram que a fé dessas mulheres é composta pelos lugares para onde elas vão e voltam, sem seguirem rigorosamente o que os autores escrevem sobre igrejas orgânicas. São minorias, mas apareceram de modo a complexificar a ideia do que seria sua fé. A Bíblia, porém, parece forte, tão forte que ultrapassa Jesus e o Espírito Santo dentro das crenças e aparece como a motivação principal dessas muIheres: a busca por uma "teologia mais bíblica". Estas mulheres então percebem coerência entre uma teologia bíblica e o maior espaço para mulheres, de modo bastante livre, pois estas não citam autoras da área de teologia feminista. A fonte de conhecimento destas são, comumente, de pastores homens, que não possuem discurso pró-feminismo e denominações que não possuem histórico teológico ou de liderança feminina nas comunidades. Então, mesmo sendo mulheres intelectualizadas, estas não têm muito acesso à teologia feminista e constroem rotas de trânsito e pensamento por conta própria.

Ainda assim, detalhando um pouco mais a população destas muIheres que vão a igrejas orgânicas, vimos que as motivações não são iguais entre as que dizem somente ser membros de igrejas orgânicas e aquelas que também vão a igrejas denominacionais. As mulheres que vão a igrejas orgânicas priorizam a "menor hierarquia" e a "presença da família", e em terceiro lugar a "teologia mais bíblica", enquanto as que se dizem membros de igrejas denominacionais privilegiam a "teologia mais bíblica", depois a "presença da família” e, em seguida, a "menor hierarquia". Devido ao grande número de mulheres que ainda se consideram membros de igrejas denominacionais, o foco na "teologia bíblica" sobe novamente para a primeira posição. 
Contudo, percebemos que as mulheres que buscaram as igrejas orgânicas pela "menor hierarquia" e pelo "maior espaço para mulheres" são as que mais se consideram membros de igrejas orgânicas, e que não possuem nenhum vínculo com instituições religiosas. Logo, essa adesão a igrejas orgânicas que leva ao rompimento com as instituições religiosas está relacionada ao desejo de maior igualdade de gênero e de oportunidades, mesmo sendo estas mulheres brancas e já possuírem mais espaço social que as mulheres - e os próprios homens - de pele negra.

Tanto mulheres que estão em igrejas orgânicas e mulheres que apenas visitam igrejas orgânicas indicam a família como central. A família é essencial tanto para mulheres solteiras quanto casadas, o que demonstra o lugar social da mulher como aquela que organiza a casa. E, na questão da "teologia bíblica", apesar de termos muita ênfase nesse aspecto dos/as autores/as que escrevem sobre igrejas orgânicas, também não faz com que elas rompam com a igreja denominacional. A autonomia destas mulheres é bastante alta para sua escolha religiosa. As respondentes dissertam que a teologia mais bíblica anda ao lado da menor hierarquia para estas. O que demonstra motivações de gênero em todos os pontos relatados pelas fiéis. Dessa maneira, essa pesquisa encontra seu resultado ao perceber essas motivações de gênero, mas abre diversas perguntas para outras oportunidades. Uma delas é fundamental: como é a relação entre a igreja denominacional e a orgânica para estas mulheres? Os limites, que pareciam muito claros para os/ as autores/as citados/as, na verdade são mais fluidos nas falas dessas mulheres que responderam o survey. Talvez, nesse sentido, seja necessária uma pesquisa qualitativa que encontre detalhes que não foram constatados no survey.

Outra questão levantada é sobre a família destas mulheres - quem são seus integrantes, para quais igrejas vão, etc. - que pode nos ajudar a aprofundar essa relação de gênero que aparece tão forte. Um estudo mais detalhado sobre as crenças minoritárias dessas mulheres e daquelas periféricas que fazem parte dessas igrejas também é crucial e necessita de mais aprofundamento futuro. Contudo, as análises dessa pesquisa já nos apontam para possibilidades de melhor acolhimento às demandas dessas mulheres, maior conhecimento de suas histórias e de caminhos para a maior igualdade de gênero. 


\section{BIBLIOGRAFIA}

COLE, Neil. Igreja Orgânica: Plantando a fé onde a vida acontece. São Paulo: Habacuc, 2007. COUTO, Márcia Thereza. Na trilha do gênero: pentecostalismo e CEBs. Estudos Feministas, v. 10, n. 2, 2002, p. 357-369.

DALE, Felicity. The Black Swan Effect: A Response to Gender Hierarchy in the Church. Austin: Createspace Independent Publishing Platform, 2014.

FERNANDES, Rubem César. Novo nascimento: os evangélicos em casa, na igreja e na política. Mauad Editora Ltda, 1998.

FERNANDES, Silvia. Mudança de religião no Brasil: desvendando sentidos e motivações. São Paulo: Palavra e Prece, 2008

IBGE. Estatísticas do CENSO 2010. Disponível em: <http://www.ibge.gov.br/home/ estatistica/populacao/cens02010/caracteristicas_religiao_deficiencia/caracteristicas_religiao_deficiencia_tab_pdf.shtm>. Acesso em: 28 mai. 2019.

MACHADO, Maria das Dores Campos; FIGUEIREDO, Fabiana Melo de. Gênero, religião e política: as evangélicas nas disputas eleitorais da cidade do Rio de Janeiro. Ciencias Sociales y Religión/Ciências Sociais e Religião, v. 4, n. 4, 2000, p. 125-148.

MACHADO, Maria das Dores Campos; MARIZ, Cecília. Representações e relações de gênero nos grupos pentecostais. Estudos Feministas, v. 13, n. 2, 2005, p. 387-396.

MARIANO, Ricardo. Usos e limites da teoria da escolha racional da religião. Tempo Social, São Paulo, v. 20, n. 2, p. 41-66, nov. 2008

SIMSON, Wolfgang. Casas que transformam o mundo: Igrejas nos lares. Curitiba: Esperança, 2014.

SOUZA, Sandra Duarte de. Mulheres evangélicas na política: tensionamentos entre o público e o privado. Horizonte, v. 13, n. 39, 2015, p. 1261-1295.

SOUZA, Sandra Duarte de. Religião e secularização: o gênero dos discursos e das práticas das mulheres protestantes. In: SOUZA, Sandra Duarte de (Org.). Gênero e Religião no Brasil: ensaio feminista. São Bernardo do Campo: Universidade Metodista de São Paulo, 2007.

SOUZA, Sandra Duarte de. Trânsito religioso e construções simbólicas temporárias: uma bricolagem contínua. Estudos de Religião, v. 15, n. 20, 2001, p. 111-120.

VILHENA, Valéria Cristina. Pela voz das mulheres: uma análise da violência doméstica entre mulheres evangélicas atendidas no Núcleo de Defesa e Convivência da Mulher Casa Sofia. São Bernardo do Campo: UMESP, 2009.

VIOLA, Frank. Cristianismo Pagão: Origens das práticas de nossa igreja moderna. São Paulo; Abba Press, 2010.

Submetido em: 24-9-2019

Aceito em: 3-10-2019

Mandrágora, v.25, n. 2, 2019, p. 109-125 